\title{
AC 2008-2089: MEETING THE MENTORING NEEDS OF NEW FACULTY: AN INTERDISCIPLINARY EXPERIENCE
}

B. Elizabeth Jones, Tarleton State University

Denise Martinez, Tarleton State University 


\title{
Meeting the Mentoring Needs of New Faculty: An Interdisciplinary Experience
}

\begin{abstract}
Every new job presents its challenges, especially when an employee has the feeling of being isolated. This paper will describe how a campus-wide faculty mentoring and networking initiative evolved from a one-day new faculty orientation into a university-supported new faculty cohort program utilizing web resources, brown-bag lunch series, and faculty development workshops. This cohort is not limited to engineering, but is an interdisciplinary group spanning several colleges within the university. The cohort started with faculty who met at the orientation and scheduled monthly informal gatherings at which they discussed general first-year experience and acclimation issues. The group then expanded to include mentors, including the Faculty Senate President and colleagues of the initial members. The addition of the Faculty Senate President as a mentor to the new faculty cohort enabled visibility of these new faculty issues to the faculty at large as well as to the administration. The group now serves as an advisory group for the Faculty Development Senate Subcommittee. The concept of the evolution from an informal group gathering periodically to discuss new faculty issues to a university recognized association of new faculty and mentors is one of developing a centralized resource enabling the smooth transition of new faculty through self-help and the guidance and knowledge of seasoned faculty.
\end{abstract}

\section{Background and Institutional Expectations}

This effort began very casually, almost accidentally, when a group of newly hired faculty members met at the New Faculty Orientation provided by the university. [University Name] is a midsized regional university serving a largely rural community in [location]. The university is growing and has recently added its first doctorate degree, an Ed.D. in Educational Leadership and Policy Studies, as well as undergraduate degrees in engineering. As the university expands, so do the expectations placed on the faculty. [University Name] has traditionally been a teaching institution, but it is evolving into a teaching and research institution. Thus, the tenure and promotion standards of the university are requiring more emphasis in the area of research. Therefore, the expectations on the new faculty today are different from new faculty of 10 years ago. Another issue facing new faculty is the simple logistics of university operations and teaching/research efforts. Across the university, the level of administratively directed mentoring of new faculty varies greatly. For example, in the College of Education, mentors are formally assigned to new faculty members to help with day-to-day operational issues, whereas in other departments the faculty are simply handed the keys to their offices. Standard operational issues such as how to write a syllabus, how to submit grades, where to find research opportunities, how to incorporate technology into the classroom, where to find office supplies, are often not addressed by departmental administration. The establishment of an informal mentoring and networking group helps fill the gaps that exist for many new faculty, and the interdisciplinary nature of the group provides a broader view of university operations and expectations. 


\section{Year 1: New Faculty Orientation and Regular, Informal Meetings}

Every fall [University Name] provides a New Faculty Orientation all-day workshop covering employment information (parking and campus security, network computer use, employee benefits overview) and an introduction to key Academic Affairs personnel and expectations. During this workshop in the fall of 2006 several of these new faculty interacted, and since they were the only ones they knew on campus these new faculty maintained contact over the next month. The members of the group quickly realized that the New Faculty Orientation, while covering the basics, left many gaps about their understanding of their new positions. Thus, the group decided to start having regular lunch meetings about every two weeks.

Approximately two months into the semester, several of the new faculty members participated in a system-wide junior faculty research workshop. The university system held its second annual junior faculty research workshop. The purpose of the workshop was to increase the interaction of junior faculty with peers system-wide and develop partnerships among common research and educational interests. The system research workshop also discussed strategies, specific to junior faculty, for research funding and success. At this event, the new faculty had the opportunity to meet some junior faculty (non-tenured, but at [University Name] for more than a year) from other disciplines at [University Name] and saw them as an obvious resource in their endeavor to acclimate to life at [University Name]. The new faculty group then invited these junior faculty to join their cohort. With the addition of junior faculty, the new faculty found instant mentors. The junior faculty helped provide solutions and information that the new faculty might have had difficulty finding on their own. While all of these junior faculty served as passive mentors to new faculty in general; most of the junior faculty developed active mentoring roles within the group and many of them extending outside their disciplines to do so.

During the first year (2006-07), with eight consistent members from the departments of engineering, education, social work, psychology, nursing and English, the group continued to hold regular informal meetings every two weeks. The cohort was a casual group with no formal structure. The frequent meetings allowed the members to network with people from various departments and helped them to build a camaraderie composed of those facing challenges of coping in their new environment. With one of the junior faculty members being the President of the Faculty Senate, issues discussed in these informal meetings were brought to the Faculty Senate. Over the summer, the cohort decided to organize the structure of the group and established officers.

\section{Year 2: Ongoing Cohort and Growth}

For year two (2007-08), the cohort added three new members: one from agriculture, one from nursing, and one from education. The cohort officers attended the university-sponsored all-day New Faculty Orientation in order to let the new faculty know about the cohort. In spite of the officers attending the New Faculty Orientation, the primary mechanism for recruiting new members was by association with existing members. 
At the first meeting of the fall semester, the group discussed becoming a formal faculty organization. However, the group came to the consensus that they should not do so because formal organizations must document meetings. This group chose to protect the free exchange of information among the participants, thus maintaining anonymity as much as the members desired, and also to minimize the required time commitment.

Also prior to the fall '07 semester, Faculty Senate members held a retreat to brainstorm objective items for the upcoming academic year. Independent of the existence of the New Faculty Cohort, Senate members resoundingly noted a need for faculty support efforts, particularly for new and junior faculty. The Senate President was then able to connect the cohort issues with the Senate objectives. The cohort members interact with other junior faculty who do not participate in the cohort and provide feedback representing their needs to the senate subcommittee addressing faculty development resources. As a result, a faculty resources website is being developed and survey data is being gathered regarding the highest need areas for new and junior faculty. This data will be used to drive periodic (e.g., monthly) workshops and brown bag lunch series. These faculty resource efforts are being hosted and implemented by the Center for Instructional Technology and Distance Education. Thus, it requires minimal time investment by the new faculty cohort members.

Most recently, expansion of the cohort has resulted in the formation of the Junior Faculty Writers Group. The focus of this group is to provide a framework for peer review of manuscripts in various stages of the writing process, review journal or conference papers, grant proposals, book chapters, academic portfolios, or any other scholarly works. The group is not only an extra set of editing eyes, but also a source of encouragement for each other to produce high quality manuscripts/scholarly work. The group also acts as a network to foster collaboration and scholarly work across the academic disciplines.

\section{Meeting Discussion Topics}

During the first year of the cohort, discussion topics included assimilation issues such as adjusting to life in a new/small town, learning about faculty resources on campus, learning the record keeping/documentation expectations of the university, and understanding the department and university expectations of teaching and scholarly activity during a faculty's "honeymoon period" and thereafter. Yearly, but usually more frequently, reoccurring discussion topics include tenure expectations in various departments and potential research collaboration and topics. During almost every meeting there was an exchange of ideas on classroom experiences such as dealing with difficult students, learning, assessment, syllabi, and the use of technology. Several of the new faculty were from the College of Education and were able to offer pedagogical advice to other faculty who had no formal training in education. It is frequently overlooked by the university that having a terminal degree in a particular field may make someone an expert in that field; it does not necessarily make for a good educator in that field. The faculty members from the College of Education were instrumental in encouraging the other new faculty to explore various pedagogies and to find one that was right for each instructor/class. 


\section{Sustainability}

For future years, the cohort intends to make a brief presentation at the new faculty workshop in order to recruit new members as well as to make new faculty aware of the resources available to them. The evolution of the group will be that the 'veteran' members give back by providing mentoring, advice, and networking to newer members. Leadership positions will be held by the newer faculty in order to lead the cohort in the direction of the needs of the new faculty and veteran members will step back and allow the cohort to evolve to meet the current need. The current intent is for this group to continue to meet regularly and to continue to provide guidance and facilitate workshop development that will have a broader impact across campus.

\section{Comparison}

Prior to the founding of the New Faculty Cohort in the fall of 2006, [University Name] had little or no uniform formal mentoring and acclimating new faculty to the university aside from a oneday orientation that included campus security and benefits information. A few examples of formal mentoring existed, such as in the College of Education, but the pervasive attitude amongst departments was the hands off, see you at evaluation approach.

The cohort took an active rather than passive approach to finding a solution. With the relatively small size of the New Faculty Cohort, the faculty members have more control over discussion topics and fulfilling each member's specific needs. Instead of waiting for the administration to fix the university program, these new employees have created a positive, interdisciplinary, information-abundant work environment for themselves.

\section{Conclusion}

The cohort is only in its second year of existence; therefore, it is too early to tell if the retention rate of new faculty at [University Name] is improving as a result of this cohort. It is also too early to tell if the faculty members participating in the cohort have a higher proposal submission rate or greater success as compared to their predecessors. However, it is worth noting that none of the new faculty from Year 1 or Year 2 of the cohort has left the university. While there is no statistical data available yet for the measure of the success of the cohort, the members all believe that their job satisfaction is significantly higher as a result of being a member of this group.

The cohort turned out to be a very synergistic effort among its participants with each member benefiting from the knowledge and experiences of the others. Because the meetings are casual, social gatherings, it does not detract from the regular obligations of the faculty member. The meetings were opportunities to get out of the office, have a little fun with friends, and learn a little about how to perform your job more efficiently. This effort was the result of new faculty who simply took the initiative to take action on perceived gaps in their understanding of how to do various tasks required of faculty. Even though this is a small group, it has had and continues to have a broader impact across campus, even to those who are not active participants in the cohort. 